\title{
Peran Incinerator Dalam Pencegahan Pencemaran Laut Di KM. Tanto Bersama
}

\author{
Andi Hendrawan ${ }^{1 *}$ \\ ${ }^{1}$ Akademi Maritim Nusantara; Jl Kendeng 307 Cilacap, telp. (0282)50701154 \\ * Corresponding Author. E-mail : andihendrawan007@gmail.com.Telp:08122741634
}

\begin{abstract}
Abstrak
Pencemaran lingkungan telah menjadi isu global, perbaikan kualitas menjadi bahan yang tak habis habisnya, disisi lain kebutuhan manusia akan energi menjadi salah satu sebab timbulnya pencemaran. Laut yang bersih merupakan impian dan harapan agar bisa kembali bisa menikmati alam yang segar dan laut yang bersih. Tujuan dari penelitian ini adalah untuk mengetahui peran incinerator dalam pencegahan pencemaran laut Di KM. Tanto Bersama. Penelitian ini merupakan penelitian survei dengan pendekatan kualitatif. Penelitian dilakukan di KM Tanto Bersama. Penelitian dilakukan dengan skala waktu atau time series. Hasil menunjukkan bahwa incinerator memiliki peran yang sangat penting dalam pencegahan pencemaran laut sehingga keberadaan incinerator menjadi suatu kewajiban diatas kapal.
\end{abstract}

Kata Kunci: Pencemaran, Incinerator

\begin{abstract}
Environmental pollution is a global issue, the improvement of the quality of materials is endless, on the other hand, human labor will be one of the causes of pollution. Clean seas are dreams and hopes to be able to enjoy fresh nature and clean seas again. This research is a survey research with a qualitative approach. The research was conducted at KM Tanto Bersama. The research was conducted with a time scale or time series. The results show that the presence of incinerators is very helpful in marine pollution. So the existence of an incinerator becomes an obligation on the ship.
\end{abstract}

Keywords: Pollution, Incinerator

\section{PENDAHULUAN}

Peranan transportasi laut di Negara Indonesia sangatlah penting. Kapal menjadi alternatif utama bagi para pengguna jasa transportasi dibandingkan dengan transportasi darat dan udara, karena selain jumlah barang atau muatan yang dibawa lebih banyak juga harga yang ditawarkan lebih murah. Salah satu permasalahan yang timbul dalam dunia pelayaran dan menjadi perhatian utama adalah pencemaran lingkungan di laut. Pengoperasian kapal diharapkan dapat ikut serta dalam menjaga kelestarian lingkungan di laut dalam hal pembuangan limbah kapal atau bahan lainnya yang dapat mengakibatkan rusaknya pencemaran di laut. Pencegahan pencemaran pada suatu kapal bukan hanya tergantung dari deck department saja tetapi engine department pun mempuyai peranan ikut menjaga 
masalah pencemaran, karena itu limbah-limbah dari kapal tersebut dalam pembuangan memerlukan pengolahan lebih lanjut.

Pencemaran laut ditimbulkan dari pembuangan limbah. Limbah tersebut antara lain minyak lumas kotor, bahan bakar, dan sampah padat. Sampah merupakan faktor dominan penyebab pencemaran di laut dan berdampak buruk terhadap lingkungan laut dan biota didalamnya. Kerusakan lingkungan laut diakibatkan oleh pembuangan limbah sampah dan minyak kotor yang tidak sesuai dengan prosedur penanganan dan regulasi yang telah ditetapkan. Untuk mengurangi dampak pencemaran lingkungan laut, kapal-kapal yang beroperasi dengan spesifikasi berat minimal GT 400 diwajibkan memiliki pesawat bantu incinerator sesuai dengan Peraturan Menteri Perhubungan Nomor PM 29 Tahun 2014 (Hikmah, 2013)

Kemajuan yang begitu pesat yang terus menerus serta persaingan teknologi modern hingga mampu menciptakan pesawat bantu yang ada di atas kapal yang disebut Incinerator, yaitu alat yang dipergunakan untuk membakar kotoran minyak lumas, bahan bakar dan sampah serta kotoran lainnya yang dapat dibakar khususnya yang berada di kamar mesin. Sebelum dibakar minyak lumas maupun kotoran yang berada di got-got kamar mesin di isap masuk ke dalam OWS (Oily Waters Separator). OWS adalah alat pemisah minyak dengan air, air yang dibuang ke laut dengan kadar tidak lebih dari 15 ppm, sedangkan minyak kotor hasil pemisahan ditampung dalam Waste Oil Tank. Tetapi pada kenyataannya banyak dijumpai pelanggaran-pelanggaran yang dilakukan oleh para pengoperasi kapal antara lain: melakukan pembuangan (dumping) tidak sesuai dengan peraturan yang berlaku, melakukan pembuangan muatan dengan sengaja, melakukan pembuangan tanpa menggunakan peralatan pencegahan pencemaran, melakukan pembuangan air got dengan menggunakan peralatan pencegahan pencemaran yang tidak berfungsi, dengan melakukan pelanggaran tersebut maka akan menimbulkan kerugiankerugian baik dari pihak pemilik kapal, pihak perusahaan dan bagi negara yang lingkungan lautnya mengalami pencemaran.

Sebagaimana yang sudah ditetapkan dalam Marpol 73/78 Annex 1 : tentang peraturan-peraturan untuk pencegahan pencemaran oleh minyak. Oleh karena itu perawatan terhadap incinerator perlu dilakukan (Kuncowati, 2019). Dengan melakukan perawatan dan perbaikan secara rutin dan sesuai dengan prosedur yang benar akan memberikan keuntungan yang ekonomis bagi perusahaan serta ikut serta dalam usaha menjaga lingkungan laut (Hakim et al., 2020). Menurut American Society for Testing and Materials tentang Standart Specification for Shipboard Incinerators (2010) Incinerator adalah fasilitas kapal yang berupa tungku pembakar yang digunakan untuk membakar limbah padat dari dapur maupun limbah cair dari pengoperasian kapal seperti Sludge Oil, Cargo Residu, limbah operasional dan lain sebagainya. Incinerator dipasang dan ditempatkan sesuai dengan peraturan dari Marine Environment Protection Committee (MPEC)(Cho et al., 2020). Penggunaan alat incinerator akan dapat mengurangi dampak dari negatif proses pembakaran diruang terbuka seperti asap, bau, radiasi dan panas yang dihasilkan dari pembakaran serta akan membuka upaya pemanfaatan energi panas hasil dari pembakaran sampah tersebut. Suhu yang didapatkan pada proses pembakaran alat incinerator dapat mencapai 500 - 10000C sehingga sampah yang 
dibakar tersebut dapat menjadi abu(Lasmana et al., 2021). Struktur luar incinerator merupakan komponen Incinerator yang terdapat dibagian luar. Dalam instalasi ini pada penataan Incinerator tentunya terdiri dari beberapa bagian peralatan atau permesinan yang merupakan satu-kesatuan, tanpa adanya peralatan-peralatan tersebut tentunya sistem penataan instalasi Incinerator ini kurang efisien.Penempatan Incinerator biasanya ditempatkan pada ruangan yang membutuhkan sirkulasi udara yang cukup dan letaknya jauh dari mesin induk, hal ini dikarenakan untuk menghindari hal-hal yang tidak diinginkan. Pada struktur bagian dalam Incinerator terdiri dari komponen-komponen yang secara struktural terdapat dibagian dalam Incinerator. Dari latar belakang diatas peneliti ingin mengetahui peran incinerator dalam pencegahan pencemaran laut khususnya Di KM. Tanto Bersama.

\section{METODE PENELITIAN}

Metode kualitatif lebih menekankan pada pengamatan fenomena dan lebih meneliti ke subtansi makna dari fenomena tersebut. Analisis dan ketajaman penelitian kualitatif sangat terpengaruh pada kekuatan kata dan kalimat yang digunakan. Oleh karena itu, Fokus dari penelitian kualitatif adalah pada prosesnya dan pemaknaan hasilnya. Perhatian penelitian kualitatif lebih tertuju pada elemen , objek, dan institusi, serta hubungan atau interaksi di antara elemen-elemen tersebut, dalam upaya memahami suatu peristiwa, fenomena (Mohamed et al., 2010). Penelitian ini merupakan penelitian survei dengan obyek penelitian di Kapal KM Tanto Bersama. Menurut Sugiyono dalam Wibowo (2021) Penelitian deskriptif yaitu mengumpulkan data berdasarkan faktor- faktor yang menjadi pendukung terhadap objek penelitian, kemudian menganalisa faktorfaktor tersebut untuk dicari peranannya Penelitian kualitatif merupakan penelitian yang berhubungan dengan ide, persepsi, pendapat, kepercayaan orang yang akan diteliti dan kesemuanya tidak dapat diukur dengan angka. Dalam penelitian ini, teori yang digunakan dalam penelitian tidak dipaksakan untuk memperoleh gambaran seutuhnya mengenai suatu hal menurut pandangan manusia yang telah diteliti.

Penelitian dengan cara mengamati pentingnya Incinerator dalam pencemaran laut selama berlayar. Morrisan (2012) menyatakan bahwa penelitian survei adalah penelitian yang dilakukan pada populasi besar maupun kecil, tetapi data yang dipelajari adalah data dari sampel yang diambil dari populasi tersebut, untuk menemukan kejadian-kejadian relatif, distribusi, dan hubungan-hubungan antar variabel sosiologis maupun psikologis. Dalam penelitian survei, peneliti menanyakan ke beberapa orang (responden) tentang keyakinan, pendapat, karakteristik suatu obyek dan perilaku yang telah lalu atau sekarang. Metode Penelitian survei berkenan dengan pertanyaan tentang keyakinan dan perilaku dirinya sendiri.

Semua anggota sampel atau resonden dalam peneitian survei menjawab pertanyaan yang sama. Penelitian survei mengukur nilai beberapa variabel, menguji beberapa hipotesis tentang perilaku, pengalaman dan karakteristik suatu obyek. Penelitian survei pada umumnya adalah penelitian korelasi. Menurut David Kline dalam Morrisan (2012) umumnya penelitian survei dilakukan untuk mengambil sebuah generalisasi dari pengamatan yang tidak terlalu mendalam. Walaupun tidak 
seperti pada metode eksperimen yang memerlukan kelompok kontrol, generalisasi pada penelitian survei yang dilakukan dapat lebih akurat bila digunakan pada sampel yang mewakili (representatif). Penelitian ini merupakan penelitian kualitatif dengan metode konten analisis yaitu mengamati isi dari stiap kegiatan yang dapat dilakukan dan peran apa yang bisa dilakukan oleh incinerator dalam upaya mencegah pencemaran laut.

\section{HASIL DAN PEMBAHASAN}

\section{Komponen-Komponen Utama Pada Incinerator}

Cooling Fan, Pada incinerator cooling fan berfungsi sebagai berikut untuk mencegah terjadinya overheating ( panas berlebihan ) pada unit utama Incinerator, untuk menjaga combution chamber dari kurangnya tekanan udara sehingga pembakaran dapat terjadi secara sempurna, untuk menurunkan suhu gas buang waste oil burner dan auxiliary burner dirancang untuk berhenti ketika cooling fan tidak beroperasi secara otomatis. Hal ini didasarkan pada segitiga api, jika salah satu komponen ini tidak ada maka reaksi pembakaran tidak akan terjadi(Santosa et al., 2021).

Waste oil selenoid valve terletak didepan waste oil burner, untuk membuka dan menutupnya katup ini bekerja secara otomatis yang dikontrol oleh waste oil burner ketika Incinerator mati, atau terjadi kegagalan pembakaran pada Incinerator maka flame eye akan memerintahkan waste oil selenoid valve untuk menutup. Hal ini dimaksudkan untuk mencegah bocornya waste oil (minyak bekas) kedalam chombution chamber.

Auxiliary burner digunakan sebagai pembakar pertama kali untuk membakar waste oil (minyak bekas) agar didapat hasil pembakaran yang sempurna, ini digunakan juga untuk membakar minyak bekas yang mengandung banyak air dan kotoran lainnya. Auxiliary burner menggunakan diesel oil (DO) sebagai bahan bakarnya. Auxiliary burner bekerja pada saat pertama kali penyalaan dan akan berhenti apabila waste oil burner menyemprotkan bahan bakar dan api dalam dapur api sudah terdeteksi oleh flame eye sehingga sinyal dari flame eye akan diteruskan kekontraktor selanjutnya akan memutus arus ke auxiliary burner.

Selenoid pump merupakan tipe pompa reciprocating yang berfungsi untuk menaikkan tekanan bahan bakar diesel oil untuk auxiliary burner pada Incinerator. Ketika adanya tegangan listrik sebesar 100 volt pada electromagnetic coil, maka akan terbentuk medan magnet dan akan menggerakkan plunger naik dan turun, gerakan dari plunger akan menggerakkan piston yang kemudian akan menghisap dan menekan minyak untuk disupplay pada waste oil burner.

Waste oil burner merupakan peralatan yang berfungsi untuk menyemprotkan minyak kotor kedalam ruang bakar, minyak kotor (waste oil) masuk kedalam burner disertai dengan udara bertekanan sebesar $0,9 \mathrm{~kg} / \mathrm{cm}^{2}$ sehingga minyak kotor (Waste oil) yang disemprotkan oleh waste oil burner akan berbentuk kabut. Hal ini dimaksudkan agar minyak kotor dapat dengan mudah terbakar.

Flame Eye, peralatan ini berfungsi untuk memberikan signal peringatan jika dalam pengoperasian Incinerator terjadi kegagalan, ketika flame eye tidak mendeteksi adanya pembakaran atau terjadi kegagalan pembakaran maka secara 
otomatis flame eye akan memutuskan aliran listrik yang terdapat pada system Incinerator dan alarm peringatan akan bekerja setelah 3,5 detik.

Exhaust gas thermostat merupakan alat bantu yang berfungsi untuk mendeteksi temperatur gas buang pada pesawat bantu Incinerator, hal ini bertujuan untuk mencegah adanya panas hasil pembakaran yang berlebihan. Jika Exhaust gas thermostat mendeteksi adanya panas yang berlebihan maka alat ini akan memotong arus listrik pada system incenerator sehingga Incinerator akan berhenti beroperasi dan alarm peringatan akan berbunyi.

Waste oil pump merupakan jenis pompa roda gigi. Pompa dan motor dihubungkan oleh sebuah coupling, pompa ini digunakan untuk menghisap dan menekan bahan bakar atau minyak kotor (waste oil) yang berasal dari waste oil settling tank ke Burner incenerator.

\section{Bahan bakar pada Incinerator}

\section{Diesel oil (DO)}

Diesel oil digunakan pada auxiliary burner, dimana minyak ini memiliki nilai viscositas (kekentalan) yang rendah sehingga mudah untuk terbakar pada suhu normal tanpa perlu dilakukan pemanasan terlebih dahulu. Berikut disajikan skema aliran diesel oil supply:

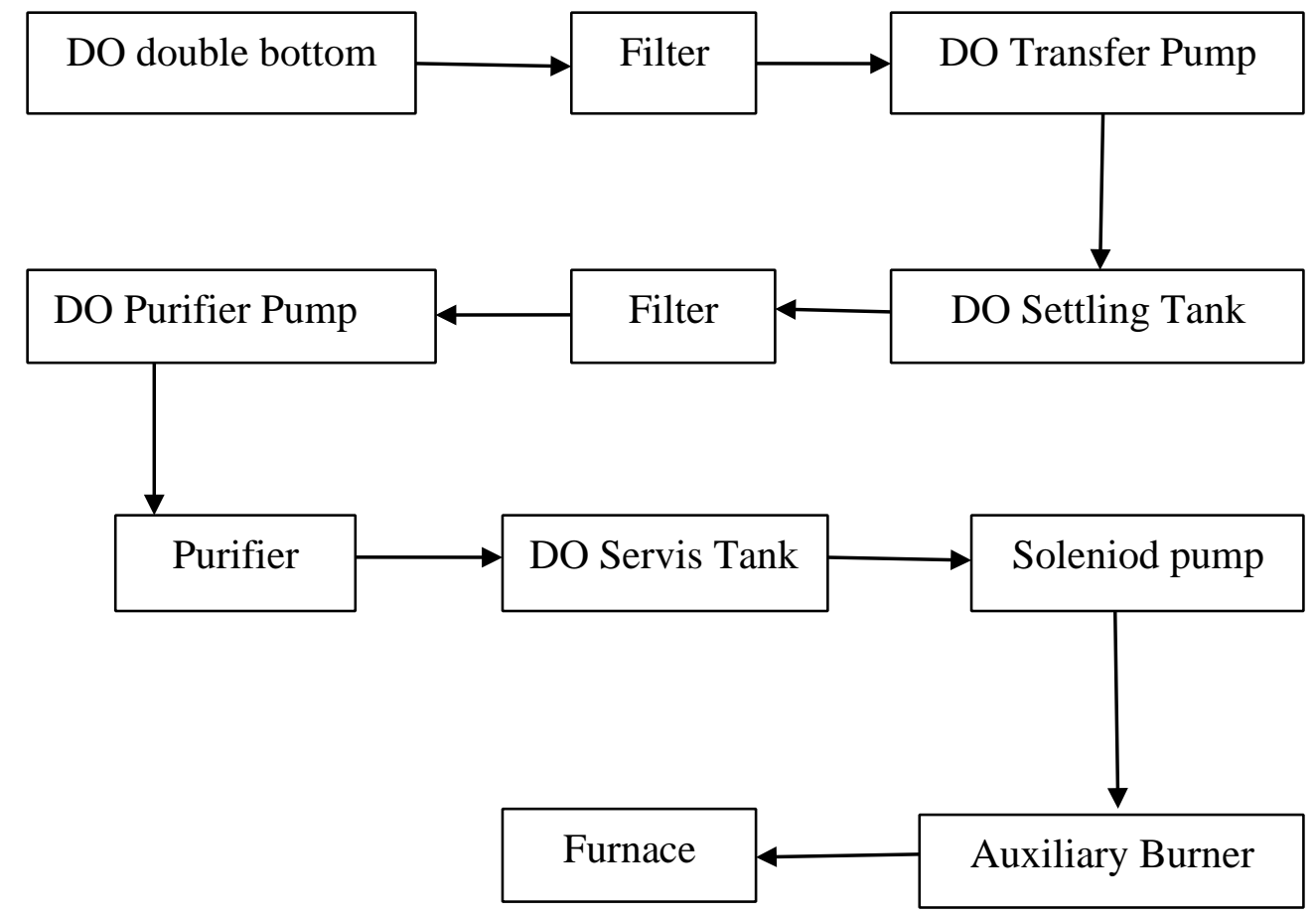

Gambar 1. Skema aliran diesel oil supply

\section{Waste oil}

Waste oil digunakan sebagai bahan bakar oleh waste oil burner, minyak ini memerlukan pemanasan hingga mendekati titik nyala, tujuan dari pemanasan yaitu untuk menurunkan nilai viscositas (kekentalan). Apabila membakar minyak dengan viscositas (kekentalan) yang masih tinggi akan memerlukan waktu yang lebih lama 
disebabkan karena berat jenis minyak masih tinggi dan titik bakar minyak masih tinggi pula sehingga untuk membakar minyak tersebut memerlukan panas yang banyak, oleh karena itu waktu pembakarannya menjadi lebih lama. Dengan pemanasan diharapkan agar minyak bekas dapat dibakar secara sempurna. Berikut disajikan Waste Oil Settling Tank di KM Tanto Bersama

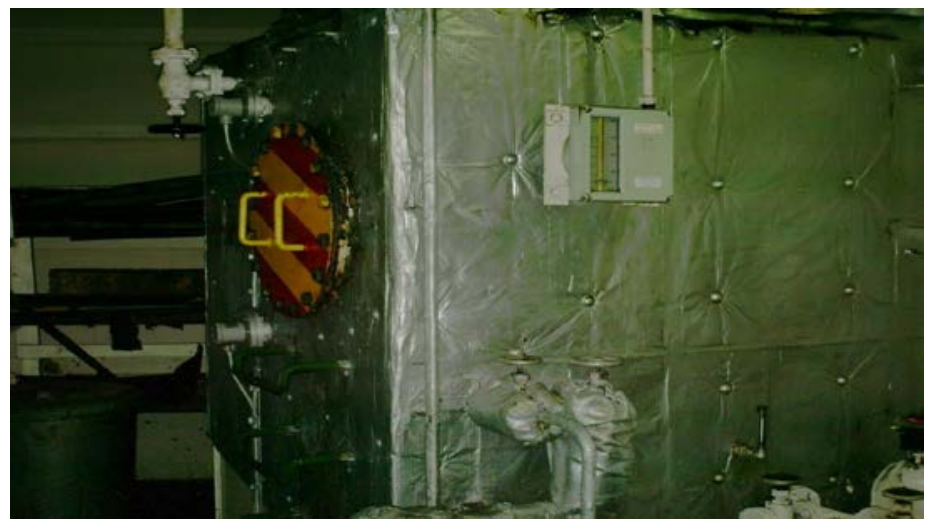

Gambar 2: Waste Oil Settling Tank di KM Tanto Bersama

\section{Prinsip Kerja Incinerator}

a. Minyak kotor ditampung di dalam Sludge tank dan minyak kotor dipanaskan dengan heater sampai suhu $60^{\circ} \mathrm{C}$, sehingga air dan minyak kotor akan terpisah. Fase air akan berada di bawah dan fase minyak akan berada di atas, ini dikarenakan perbedaan berat jenis. Berat jenis air lebih tinggi daripada berat jenis minyak.

b. Kemudian minyak kotor di transfer ke waste oil settling tank menggunakan pompa sludge. Minyak kotor dalam waste oil settling tank dipanaskan antara suhu $90-110^{\circ} \mathrm{C}$. Bertujuan agar air yang masih terdapat dalam minyak dapat dengan mudah dipisahkan agar kandungan air dalam minyak kotor yang akan dibakar serendah mungkin.

c. Sampah, majun, kertas, dan plastik dimasukkan ke dalam tempat penampungan diatas ruang pembakaran.

d. Jalankan"cooling fan"dan akan ditandai dengan lampu pada panel control akan menyala.kemudian fase pre-purge akan berlangsung yang bertujuan untuk membersihkan ruang pembakaran dan memberikan udara bersih sebelum fase pembakaran.

e. Setelah fase pre-purge selesai dilanjutkan dengan fase pembakaran. pertama kali menggunakan auxiliary burner dan waste oil burner secara bersama-sama. setelah api pembakaran kelihatan maksimal, pindah posisi switch ke posisi waste oil burner maka pembakaran hanya menggunakan waste burner saja. Sebelum membakar minyak kotor, panasi terlebih dahulu incinerator sekitar 15 menit dengan menggunakan bahan bakar DO. Setelah 15 menit pindah kran bahan bakar DO ke posisi kran waste oil burner sehingga minyak kotor mulai dibakar. Apabila minyak kotor telah terbakar ditandai dengan naiknya tekanan waste oil burner yang dapat dilihat pada manometer. Pada proses pembakaran yang pelu diingat adalah untuk mengatur aliran minyak kotor yang akan

Majalah Ilmiah Bahari Jogja 47 | http://jurnal.stimaryo.ac.id/index.php/MIBJ/ 
dibakar. Pada saat membakar minyak kotor dengan kadar kalori rendah kran pengaturan aliran minyak dibuka penuh tetapi pada saat membakar minyak kotor dengan kadar kalori tinggi maka kran harus diatur pembukaannya karena minyak kotor yang akan dibakar terlalu banyak dapat menyebabkan kerusakan didalam Incinerator. Pengaturan temperature pembakaran diatur pada suhu $300-500^{\circ} \mathrm{C}$.

f. Pada akhir pembakaran ganti posisi kran waste oil pada posisi ke DO dan pembakaran dilanjutkan sekitar 10 menit, ini bertujuan untuk membersihkan saluran pembakaran karena jika saluran pembakaran tidak dibersihkan maka pada saat Incinerator akan digunakan kembali akan susah untuk dioperasikan. Setelah pembakaran selesai dilanjutkan dengan fase post-purge yaitu menghembuskan udara bersih dari luar yang bertujuan untuk membersihkan ruang pembakaran dan mendinginkan burner.

Hasil pengamatan menunjukan bahwa incinerator bekerja dengan bail selama kapal berlayar. Sampah dapat terbakar sempurna sehingga meminmalkan pencemaran laut. Peraturan dalam upaya mencegah polusi menurut aturan internasional. Sesuai dengan MARPOL annex 1 yang di kapal, dalam rangka untuk mencegah pencemaran minyak melalui suatu instalasi yang dinamakan incinerator. Pencemaran minyak dapat dicegah melalui media alat yang dinamakan incinerator.

Kapal beroperasi maka akan timbul minyak kotor sebanyak 1\% dari jumlah bahan bakar yang dikonsumsi, hal ini dikarenakan campuran kotoran, lumpur dan air. Pada saat berlayar atau kapal beroperasi maka membutuhkan waktu yang lama maka minyak kotor atau sludge yang dihasilkan dari pengoperasian purifier akan bertambah pula, sehingga minyak kotor atau sludge tersebut akan melebihi batas maksimum dari sludge tank diatas kapal. Jika incinerator mengalami hambatan maka akan terjadi kelebihan terhadap kapasitas minyak kotor dan harus dibuang ke darat melalui kapal tongkang atau dengan mobil pengangkut didarat melalui international shore connection, hal ini dapat menambah biaya yang sangat besar bagi perusahaan. Incinerator akan bekerja dengan lancar jika hal-hal dibawah ini terpenuhi: Suhu pada waste oil settling tank antara $90-110^{\circ} \mathrm{C}$, Filter dalam keadaan bersih, Tekanan angin $0.9 \mathrm{~kg} / \mathrm{cm}$, Tekanan bahan bakar $0.5 \mathrm{~kg} / \mathrm{cm}$, Burner dapat bekerja dengan baik dalam hal ini penyemprotannya sempurna, Fan dapat beroperasi dengan normal, Flame eye bekerja dengan baik, Pompa waste oil bekerja dengan baik perawatan memainkan peranan penting di atas kapal. Melalui perawatan kita dapat mengendalikan atau memperlambat tingkat kemerosotan kapal serta pula kita dapat menjaga kelestarian laut terbebas dari pencemaran minyak.

Hal ini sesuai dengan pendapat (Dwiono et al., 2021) bahwa perawatan penting untuk meminimalkan kerusakan yang terjadi pada komponen kapal. Hasil penelitian (Amalia et al., 2021) menunjukkan bahwa masih adanya crew kapal yang belum memahami tentang prosedur penanganan sampah di atas kapal. Dengan memberikan gambaran tentang metode penanganan sampah, para crew kapal Indonesia akan memiliki pengetahuan tentang penanganan sampah di kapal sesuai dengan garbage management plan sehingga dapat meminimalkan pencemaran laut. Hal ini menunjukan bahwa incinerator yang bagus aja belum cukup, perlu 
dibarengi dengan kesadaran crew kapal tentang pencemaran laut yang artinya tidak sembarangan membuang sampah ke laut.

Keuntungan dari proses insinerasi ini adalah volume sampah akan tereduksi dengan sangat signifikan (> 65\%). Teknologi incinerator merupakan alat pemusnah sampah yang dilakukan dengan pembakaran pada suhu tinggi dan terpadu, aman bagi lingkungan, pengoperasiannya mudah dan aman, karena keluaran emisi yang dihasilkan berwawasan lingkungan. Pengunaan incenerator dapat memenuhi persyaratan dari Kementerian Lingkungan Hidup sesuai dengan Kep. Men LH No.13/ MENLH/3/1995(Dewi et al., 2020)

Peran incinaror cukup signifikan dalam pencegahan pencemaran laut, karena keberadaannya berfungsi untuk memusnahkan sampah sehingga volumenya menjadi kecil karena proses pembakaran. Penggunaaan incinerator (Suprihatin, 2018) yang baik dan efektif adalah dengan volume tidak lebih dari 0,7 m3, karena apabila volume sampah yang dimusnahkan melebihi volume yang dipersyaratkan,maka mengakibatkan kurangnya oksigen dalam tungku bakar, dimana oksigen tersebut berfungsi untuk membantu proses pembakaran di dalam tungku incenerator, sehingga pembakaran tersebut tidaklah efektif. Tujuan dari kegiatan pemusnahan sampah pada akhirnya kesehatan lingkungan, kesehatan dan keselamatan kerja crew kapal, dengan berfungsinya incinartor dengan baik dan tingkat pengetahuan dan prilaku crew kapal yang makin baik pula diharapkan tingkat keselamatan dan kesehatan kerja makin baik pula(Hendrawan, 2020)

\section{SIMPULAN}

Keberadaan incinerator dalam sebuah kapal sangat penting, karena fungsi sebagai pemusnah sampah. Karena alat ini berperan untuk mencegah pencemaran laut selain sebagai pemenuhan aturan pelayaran (MARPOL) . Karena pentingnya maka harus beroperasi dengan baik, dirawat dengan sungguh sungguh sehingga bisa bermanfaat dengan semestinya. Peran yang lebih penting selain mencegah pencemaran laut adalah menjaga kesehatan dan keselamatan crew kapal, sampah yang menumpuk merupakan sarang penyakit yang bisa menjadi sebab terjangkit suatu penyakit.

\section{DAFTAR PUSTAKA}

Amalia, P. A., Katili, A. R., \& Alkhawarizmi, M. (2021). Penerapan Garbage Management Plan Sebagai Upaya Pencegahan Pencemaran Laut Pada Mv Rio Choapa. Jurnal Maritim, 11(1), 11-23.

Cho, B. H., Nam, B. H., An, J., \& Youn, H. (2020). Municipal solid waste incineration (MSWI) ashes as construction materials-a review. Materials, 13(14), 1-30. https://doi.org/10.3390/ma13143143

Dewi, R., Hadinata, F., Sriwijaya, U., Palembang, K., \& Selatan, S. (2020). Sistem pengolahan sampah domestik dengan menggunakan incinerator drum bekas. Seminar Nasional AVoER XII 2020 Palembang, 18 - 19 November 2020 Fakultas Teknik Universitas Sriwijaya SISTEM, November, 891-896.

Dwiono, A. S., Hendrawan, A., \& Pramono, S. (2021). Perbaikan Lambung Kapal 
KM. Harima PT. CSFI-Cilacap. Dinamika Bahari, 2(1), 56-61. https://doi.org/10.46484/db.v2i1.261

Hakim, A. R., Wibowo, W., \& Astriawati, N. (2020). Sistem Pendingin Mesin Diesel Pada Whell Loader Komatsu Wa120-3cs. Jurnal Teknovasi: Jurnal Teknik Dan Inovasi, 07, 76-85.

Hendrawan, A. (2020). Program Kesehatan Dan Keselamatan Kerja Di Atas Kapal. Jurnal Sains Teknologi Transportasi Maritim, 2(1), 1-10.

Hendrawan, A., Ajun, R., Siswadi, \& Supari. (2021). Penyebab Kerusakan Electro Motor Oil Max Pump pada Mesin Induk di KM . Dharma Kartika IX. Jurnal Saintara, 5(2), 28-35.

Hendrawan, A., Pratomo, L. H., \& Siswad. (2021). Perawatan Electro Motor Oil Max Pump pada Mesin Induk KM Dharma Kartika IX. Saintara : Jurnal Ilmiah Ilmu-Ilmu Maritim, 28-35. https://doi.org/10.52488/saintara.v5i2.104

Hikmah, F. N. (2013). Rancang Bangun Alat Incinerator Tipe Batch (Menghitung Panas Pembakaran Di Primary dan Secondary Chamber Pada Proses Pembakaran Limbah Infeksius di Incinerator). 53(9), 1689-1699.

Kuncowati, K. (2019). Analisis Pengelolaan Sampah Di Kapal Dan Peran Awak Kapal Terhadap Pencegahan Pencemaran Laut Dari Kapal Di Pelabuhan Tanjung Perak Surabaya. Majalah Ilmiah Bahari Jogja, 17(1), 71-85.

Lasmana, A., Junaidi, \& Kurniawan, E. (2021). Rancang Bangun Alat Pembakar Sampah ( Incinerator ) Dengan Burner Oli Bekas. JTRAIN : Jurnal Teknologi Rekayasa Teknik Mesin, 2(1), 35-40.

Mohamed, Z. M., Abdul Majid, A. H., \& Ahmad. (2010). Tapping new possibility in accounting research, in qualitative research in accounting. Universiti Kebangsaan Malaysia, Kuala Lumpur, Malaysia, 2010.

Morrisan, M. A. (2012). Metode penelitian survei. Kencana.

Santosa, P. S., Astriawati, N., Pratama, W., Wibowo, W., \& Hartanto, B. (2021). Program Pelatihan Perlindungan Resiko Kebakaran Dengan Pengenalan Dan Penggunaan APAR. ABDIMAS UNWAHAS, 6(1).

Suprihatin, H. (2018). Efektifitas Incenerator Untuk Pembakaran Sampah Medis di RSUD Kota ABC. Dinamika Lingkungan Indonesia, 5(2), 76. https://doi.org/10.31258/dli.5.2.p.76-83

Wibowo, W., \& Astriawati, N. (2021). Sistem Pendingin Tertutup Pada Mesin Diesel Tipe Diesel MAK 8M32 Sebagai Penggerak Utama Kapal Motor LIT ENTERPRISE. Jurnal POLIMESIN, 19(1), 28-34. 